\title{
Studies in Clinical Shock and Hypotension
}

\author{
VI. RELATIONSHIP BETWEEN LEFT AND RIGHT \\ VENTRICULAR FUNCTION
}

Jay N. Cohn, Felix E. Trustani, and Ibrahim M. Khatri
From the Hypertension and Clinical Hemodynamics Section, Veterans
Administration Hospital, Washington, D. C. 20422 and the Department of
Medicine, Georgetown University Medical Center, Washington, D. C. 20007

A в S T R A C T Left ventricular end diastolic (LVEDP) and mean right atrial (RAP) pressures were recorded simultaneously in 30 patients with shock (14 acute myocardial infarction, 10 acute pulmonary embolism or severe bronchopulmonary disease, and 6 sepsis). Myocardial infarction was characterized by a predominant increase in LVEDP, pulmonary disease by a predominant increase in RAP, and sepsis by a normal relationship between LVEDP and RAP. In all three groups a significant positive correlation was noted between RAP and LVEDP, with the regression line in cor pulmonale deviated significantly toward the RAP axis and the regression line in myocardial infarction exhibiting a zero RAP intercept at an elevated LVEDP.

Low cardiac outputs with elevated LVEDP in myocardial infarction indicated severe left ventricular failure. Low outputs with elevated RAP in cor pulmonale were consistent with right ventricular overload. Although cardiac outputs often were normal in sepsis, low outputs with elevated cardiac filling pressures in some patients were consistent with a hemodynamic or humoral-induced generalized depression of cardiac performance.

Vasoconstrictor and inotropic drugs often produced a functional disparity between the two ventricles, with the gradient between LVEDP and RAP increasing, apparently because of an increase in left ventricular work or an inadequacy of left ventricular oxygen delivery. Acute plasma volume expansion with dextran in patients with pulmonary vascular disease resulted in a somewhat more rapid rise in RAP than in LVEDP. In septic and myocardial infarction shock, however, LVEDP and RAP

This work was presented in part at the Annual Meeting of the American College of Physicians, Boston, Mass., April, 1968 (Ann. Intern. Med. 68: 1153).

Received for publication 13 February 1969 and in revised form 18 June 1969. usually rose proportionally, with the absolute rise of LVEDP surpassing that of RAP. Although the absolute level of the central venous pressure thus may not be a reliable indicator of left ventricular function in shock, changes in venous pressure during acute plasma volume expansion should serve as a fairly safe guide to changes in LVEDP.

\section{INTRODUCTION}

Myocardial function may be adversely affected in shock by a number of mechanisms. Not only will myocardial infarction and pulmonary embolism directly alter cardiac performance, but hemorrhagic, traumatic, and septic shock also may be accompanied by hemodynamic evidence of myocardial deterioration (1-5). Cardiac failure in shock has been variously attributed to a reduction of coronary blood resulting from lowered aortic pressure (6-9), to the myocardial depressant effect of humoral substances $(9,10)$, and to derangements in acid-base balance $(11,12)$.

In clinical shock impairment of cardiac function is recognized by a reduced cardiac output associated with an elevated cardiac filling pressure. Because myocardial failure may supervene in shock of diverse etiologies, the central venous pressure (CVP) has been widely used in recent years as a bedside index of cardiac performance (13). Monitoring of the CVP during therapeutic trials of volume expansion has helped to separate low output states due to volume depletion from those in which impairment of myocardial function is an important contributing factor (14).

However, the CVP is a direct reflection only of right ventricular filling pressure. The causes of impaired cardiac performance in shock do not necessarily affect the two ventricles equally. Thus, myocardial infarction would be expected to result in predominant left ven- 
tricular failure (15) whereas pulmonary embolism should involve overload limited to the right ventricle (16). The effect of circulating toxins and disturbances in myocardial nutrition on the relative function of the two ventricles has not been established. Although these nonspecific insults might be expected to eventuate in biventricular failure, it is not certain that right ventricular myocardial impairment leads to circulatory effects. The classical observation of Starr, Jeffers, and Meade (17) that severe right ventricular damage does not significantly alter hemodynamics implies that the generalized myocardial damage which may develop in the course of noncardiac forms of shock could result in predominant left ventricular failure.
If left ventricular failure occurs in shock in the absence of right ventricular failure, the CVP may be a misleading guide to the adequacy of cardiac function. Indeed, volume expansion in such situations might be hazardous. In order to gain some insight into the relationship between right and left ventricular function in shock, we have been catheterizing the left ventricle as well as the right atrium in patients with shock admitted to our intensive care unit. The purpose of the present report is to analyze data obtained during simultaneous measurement of right and left ventricular filling pressures in $\mathbf{3 0}$ patients with shock. The study afforded an opportunity not only to compare left and right ventricular function in shock of various etiologies but also to

TABLE I

Clinical and Hemodynamic Data in 30 Patients with Shock

\begin{tabular}{|c|c|c|c|c|c|c|c|c|c|c|c|}
\hline \multirow[b]{2}{*}{ Patient } & \multirow[b]{2}{*}{ Diagnosis } & \multirow[b]{2}{*}{ Age } & \multirow[b]{2}{*}{ BSA } & \multirow[b]{2}{*}{ Cuff BP } & \multirow[b]{2}{*}{ MAP } & \multicolumn{2}{|c|}{ LVP } & \multirow[b]{2}{*}{ RAP } & \multirow[b]{2}{*}{ HR } & \multirow[b]{2}{*}{ co } & \multirow[b]{2}{*}{ CI } \\
\hline & & & & & & md & ed & & & & \\
\hline & & $y r$ & $m^{2}$ & $m m \mathrm{Hg}$ & $m m \mathrm{Hg}$ & \multicolumn{2}{|c|}{$m m \mathrm{Hg}$} & $m m \mathrm{Hg}$ & beats/min & lilers/min & liters $/ \mathrm{min} / \mathrm{m}^{2}$ \\
\hline G. P. & Acute MI & 54 & 1.59 & 90 & 74 & 16 & 24 & 14 & 90 & $3.68^{*}$ & 2.31 \\
\hline M. D. & Acute MI & 53 & 1.78 & $98 / 78$ & 76 & 26 & 30 & 14 & 96 & $3.67^{*}$ & 2.06 \\
\hline W. B. & Acute MI & 61 & 1.80 & 0 & 98 & 10 & 14 & 3 & 126 & 1.79 & 0.99 \\
\hline G. R. & Acute MI & 72 & 1.51 & 90 & 92 & 24 & 30 & 12 & 74 & 0.87 & 0.58 \\
\hline R. H. & Acute MI & 79 & 1.86 & 0 & 54 & 24 & 24 & 5 & 120 & 1.83 & 0.98 \\
\hline E. A. & Acute MI & 53 & 1.63 & 75 & 50 & 8 & 12 & 3 & 150 & 4.29 & 2.63 \\
\hline R. B. & Acute MI & 61 & 2.03 & $80 / 60$ & 60 & 22 & 22 & 11 & 75 & 3.47 & 1.71 \\
\hline W. P. & Acute MI & 60 & 1.59 & 0 & 86 & 11 & 16 & 8 & 108 & 3.29 & 2.07 \\
\hline L. W. & Acute MI & 72 & 2.04 & $90 / 45$ & 66 & 17 & 17 & 8 & 114 & 3.02 & 1.48 \\
\hline E. W. & Acute MI & 71 & 1.97 & $80 / 60$ & 67 & 16 & 18 & 6 & 90 & - & - \\
\hline D. T. & Acute MI & 61 & 1.64 & 80 & 85 & 36 & 40 & 11 & 85 & $3.81^{*}$ & 2.32 \\
\hline L. P. & Acute MI & 66 & 1.97 & 0 & 70 & 27 & 34 & 18 & 102 & - & - \\
\hline W. 0 . & Acute MI & 54 & 1.88 & 60 & 57 & 33 & 33 & 25 & 80 & - & - \\
\hline J.S. & Acute MI & 58 & 1.60 & 80 & 70 & 5 & 8 & 6 & 108 & 4.28 & 2.68 \\
\hline E. $\mathrm{H}$. & Pneumonia & 46 & 1.58 & 0 & 74 & 14 & 16 & 16 & 72 & 2.91 & 1.84 \\
\hline F. W. & Pulmonary embolism & 75 & 1.78 & $80 / 60$ & 48 & 1 & 2 & 4 & 80 & 4.08 & 2.29 \\
\hline L. H. & Pulmonary embolism & 65 & 1.68 & $90 / 60$ & 70 & 6 & 8 & 9 & 99 & 5.23 & 3.11 \\
\hline F. M. & Pneumonia & 46 & 1.76 & $92 / 60$ & 28 & 8 & 8 & 10 & 123 & 3.33 & 1.89 \\
\hline W. P. & Pulmonary embolism & 67 & 1.91 & 0 & 60 & 2 & 4 & 2 & 156 & - & - \\
\hline D. P. & Pneumonia & 48 & 1.35 & 80 & 48 & 4 & 4 & 3 & 108 & - & - \\
\hline J. D. & Pneumonia & 43 & 1.98 & $90 / 60$ & 56 & 12 & 16 & 16 & 88 & - & - \\
\hline J. A. & Pneumonia & 67 & 1.60 & $85 / 60$ & 70 & 6 & 6 & 0 & 86 & 3.22 & 2.01 \\
\hline J. E. & Pulmonary embolism & 63 & 1.80 & $85 / 60$ & 52 & 5 & 5 & 19 & 130 & - & - \\
\hline O. H. & Pulmonary embolism & 56 & 1.92 & $90 / 80$ & 80 & 12 & 12 & 26 & 108 & - & - \\
\hline J. R. & Septicemia & 70 & 1.72 & $80 / 40$ & 52 & 16 & 16 & 13 & 56 & $4.58^{*}$ & 2.66 \\
\hline L. E. & Septicemia & 53 & 1.74 & 0 & 76 & 8 & 12 & 5 & 112 & 4.68 & 2.69 \\
\hline W. R. & Septicemia & 42 & 1.81 & $70 / 30$ & 38 & 6 & 6 & 4 & 74 & 6.90 & 3.83 \\
\hline W. M. & Septicemia & 74 & 1.85 & 0 & 62 & 5 & 5 & 0 & 126 & 4.61 & 2.49 \\
\hline R. H. & Cirrhosis, sepsis & 51 & 1.88 & 80 & 50 & 16 & 18 & 8 & 90 & 10.70 & 5.69 \\
\hline E. P. & Septicemia & 74 & 1.39 & $60 / 40$ & 54 & 8 & 10 & 5 & 100 & - & - \\
\hline
\end{tabular}

BSA = body surface area Cuff BP = auscultatory or palpatory brachial pressure at time of diagosis; MAP = mean arterial pressure; $L V P=$ left ventricular pressure (md = mean diastolic, ed = end diastolic); $R A P=$ mean right atrial pressure; $\mathrm{HR}=$ heart rate $\mathrm{CO}=$ cardiac output $; \mathrm{CI}=$ cardiac index.

* COO measured during infusion of isoproterenol. 
monitor the changes in pressure during administration of vasoactive agents and during rapid volume expansion.

\section{METHODS}

Shock was recognized on the basis of a fall in auscultatory blood pressure accompanied by signs of inadequate peripheral blood flow and clinical deterioration of the patient's condition. Urine output was less than $20 \mathrm{ml} / \mathrm{hr}$ in all patients and most demonstrated absent or thready peripheral pulses, cool, moist skin, disturbance in sensorium, and lactic acidosis. Although auscultatory or palpatory systolic pressure was below $100 \mathrm{~mm} \mathrm{Hg}$ in all patients, some still maintained at the time of study an intra-arterial pressure within the normal range (18). Clinical data are shown in Table I. Informed consent for the procedure was obtained either from the patient or from his family.

Hemodynamic procedures were carried out either at the patient's bedside in the intensive care unit or in a special laboratory adjoining this unit. The right atrium or intrathoracic vena cava was catheterized with a polyethylene catheter advanced through a $14 \mathrm{G}$ thin-walled needle introduced in the femoral, antecubital, jugular, or subclavian veins. Left ventricular catheterization was accomplished with a precurved radiopaque red Kifa polyethylene catheter (U. S. Catheter and Instrument Corp., Glens Falls, N. Y.) introduced percutaneously by the Seldinger technique in the femoral artery and advanced retrograde through the aortic valve. Initial studies were carried out under direct vision with a Siemens portable image intensifier. However, the ease of entering the left ventricle in these patients encouraged us to attempt the procedure blindly with the aid of a catheter designed with a tight terminal loop to prevent its entry into arterial branches (19). Recent studies have thus

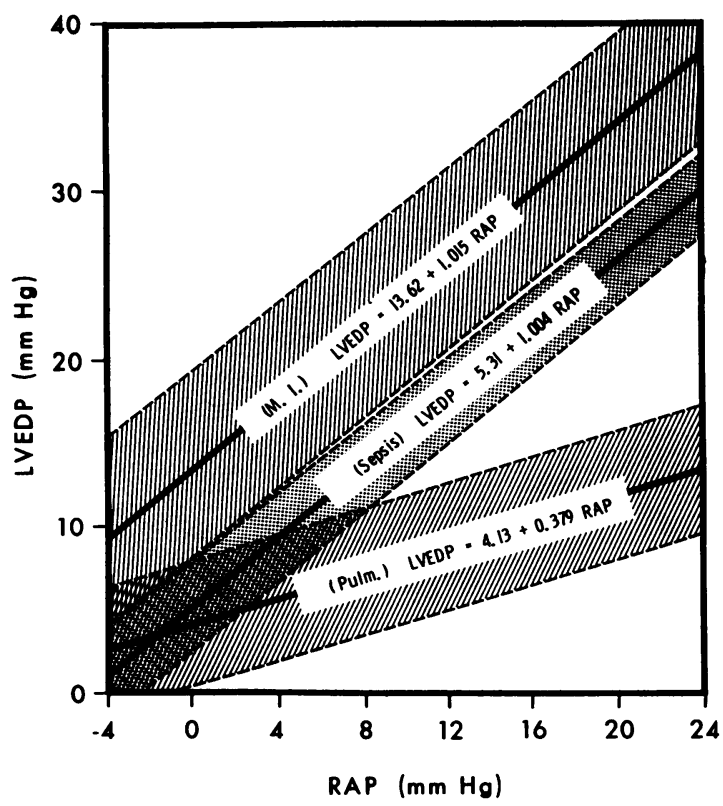

FIgURE 1 The regression lines relating left ventricular enddiastolic pressure to mean right atrial pressure in the three groups of patients. The shaded areas represent one standard error of the estimate on either side of the calculated regression lines. M.I. = acute myocardial infarction; Pulm. = pulmonary embolism or extensive pulmonary disease.

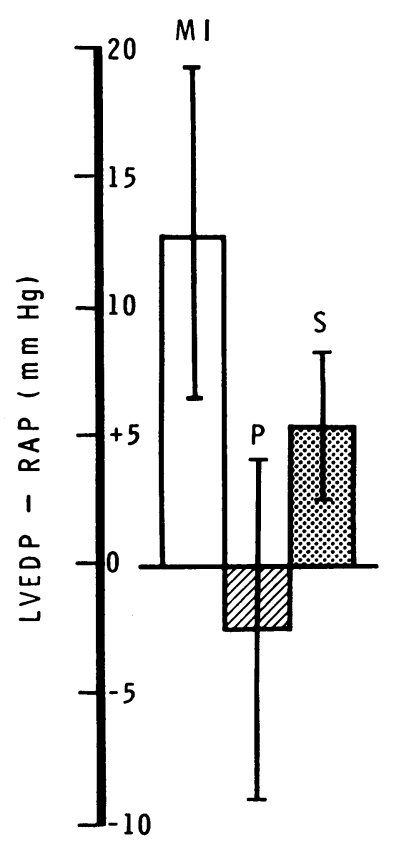

FIgURE 2 Mean and 1 SD from the mean gradient between left ventricular end diastolic pressure and right atrial pressure in the three diagnostic categories ( $M I=$ acute myocardial infarction; $\mathrm{P}=$ pulmonary embolism or extensive pulmonary disease; $\mathrm{S}=$ sepsis). The gradient in $\mathrm{MI}$ is significantly higher than in pulmonary disease $(P<0.001)$ and in sepsis $(P<0.01)$. The gradient in sepsis is greater than in pulmonary disease $(P<0.025)$.

been accomplished without fluoroscopy and with a success rate of over $80 \%$. Entry into the left ventricle often is signaled by a few ventricular premature beats which promptly disappear. In no instance in this series did an arrhythmia preclude leaving the catheter within the left ventricular cavity. A Statham P23BB strain gage was connected to the venous catheter and a $\mathrm{P} 23 \mathrm{Db}$ strain gage to the left ventricular catheter and both were positioned at the mid-chest. Pressures were recorded on a Sanborn multichannel direct writing recorder or a Waters photographic recorder (The Waters Company, Rochester, Minn.). The catheter was usually left in the ventricle for several minutes or several hours while treatment of the patient was instituted or modified. In some patients the catheter was withdrawn into the ascending aorta after left ventricular pressures were measured and then intermittently advanced back into the left ventricle during the course of treatment.

Cardiac output (CO) was measured by the indicator dilution technique. Indocyanine green dye $(5 \mathrm{mg})$ was injected as a bolus into the right atrium while left ventricular or aortic blood was withdrawn through a Gilford or Waters cuvette densitometer. $\mathrm{CO}$ was calculated by the standard Stewart-Hamilton method (20). When dye curves are markedly prolonged errors can be introduced into the calculation of blood flow because of the appearance of recirculation before the establishment of an exponential downslope of the primary curve. This potential problem was at least partially obviated in the present study by using central injection and sampling sites. Most of the curves in these patients were not unduly prolonged and exhibited a fairly normal configuration, but it is possible that in some in- 
stances the calculation of cardiac output gave a falsely low value.

Statistical analysis was carried out using standard methods for calculating correlation coefficients, straight line regressions, and the difference between means.

\section{RESULTS}

Acute myocardial infarction. Left ventricular end diastolic pressure (LVEDP) was elevated (over 12 $\mathrm{mm} \mathrm{Hg}$ ) (21) in 13 of 14 patients with shock after myocardial infarction (Table I). Left ventricular mean diastolic pressure also was usually elevated, so that a rise in pressure immediately after atrial contraction was not an important factor in the elevated LVEDP. Right atrial pressure (RAP) was elevated in nine subjects but in five others RAP was within the normal range (up to $6 \mathrm{~mm} \mathrm{Hg}$ ). RAP and LVEDP tended to vary together $(r=0.723, P<0.01)$. The regression line relating LVEDP to RAP exhibited a slope of approximately 1.0 but with a 0 intercept at an elevated LVEDP (Fig. 1). LVEDP averaged $23.0 \mathrm{~mm} \mathrm{Hg}$ and surpassed the RAP by an average of $12.7 \mathrm{~mm} \mathrm{Hg}$ (range 3-29 $\mathrm{mm} \mathrm{Hg}$ ) (Fig. 2). The ratio of LVEDP to RAP for all 14 patients averaged 2.65. CO averaged 3.09 liters $/ \mathrm{min}$ and the cardiac index (CI) averaged 1.81 liters/min per $\mathrm{m}^{2}$. The $\mathrm{CI}$ was at the lower limits of normal in two patients but was clearly reduced in the other nine patients, including three in whom measurements were made only during infusion of isoproterenol. The stroke volume was low in all patients (Table I, Figs. 3 and 4).

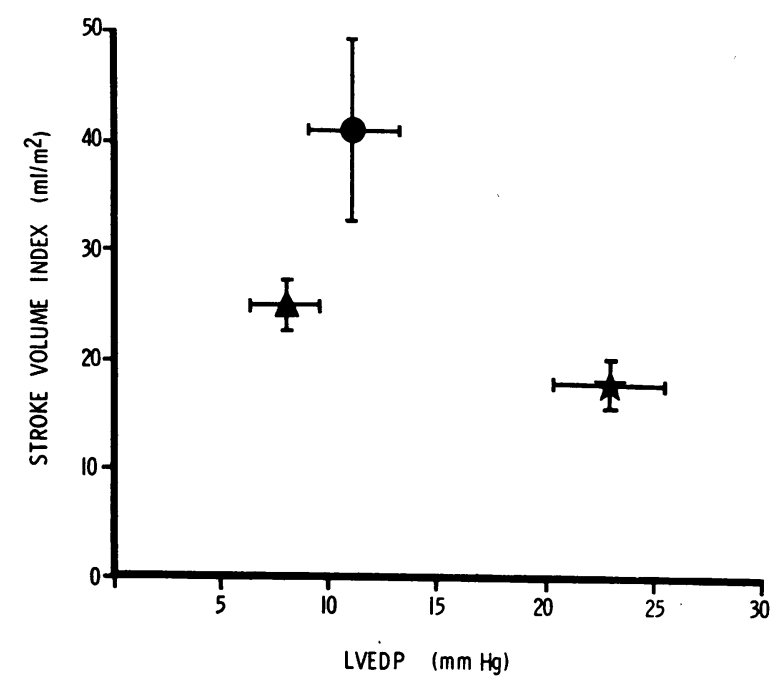

FIGURE 3 Relationship between average left ventricular end diastolic pressure and average left ventricular. stroke volume index in the three groups of patients. Star represents mean of 11 patients with acute MI, triangle, the mean of five patients with pulmonary disease, and closed circle, mean of five patients with sepsis. Brackets depict SEM for LVEDP and SVI.

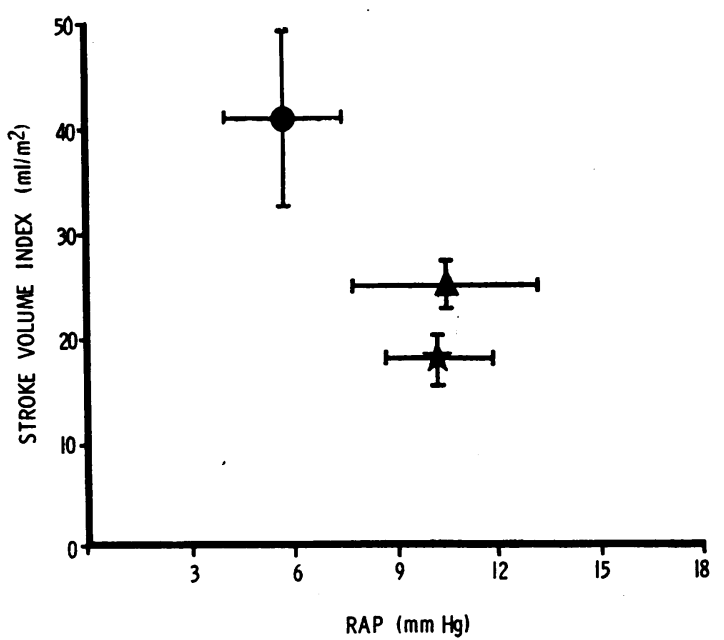

FIGURE 4 Relationship between average right atrial pressure and average stroke volume index in the same groups shown in Fig. 4.

In seven of the patients isoproterenol infusion was begun after control observations were completed ( $\mathrm{Ta}$ ble II). Infusion rate of the drug was gradually increased from 2 to $40 \mu \mathrm{g} / \mathrm{min}$ until a dose was achieved which appeared to produce the optimal hemodynamic response without inordinate tachycardia or arrhythmia. $\mathrm{CO}$, measured during isoproterenol infusion in five of the patients, increased in each instance from an average of 2.97 to 5.70 liters/min. RAP either fell or remained unchanged, but LVEDP was not consistently altered (Fig. 5). LVEDP was reduced considerably in one patient and either rose or fell slightly in four patients. In the other two patients LVEDP decreased with initiation of isoproterenol therapy but then increased sharply. In one, this apparent aggravation of left ventricular failure was related to an increase in the infusion rate of the drug, but in the other case it appeared to be a spontaneous response during a steady infusion rate. In five of the seven patients the gradient between LVEDP and RAP increased during isoproterenol administration. Heart rate usually rose during infusion of the drug, but the response of arterial pressure was variable. Mean arterial pressure (MAP) rose in some patients but fell in others despite an increase in CO.

Three patients were treated with infusions of either norepinephrine or metaraminol at a rate adequate to restore MAP to normotensive levels (Table III). Two of the patients responded with a sharp rise in LVEDP and only a small increase in RAP. The rise in LVEDP was accompanied in one patient by a slight increase in $\mathrm{CO}$, but in the other patients $\mathrm{CO}$ was not measured.

Low molecular weight dextran (Rheomacrodex, supplied by Pharmacia Laboratories, Piscataway, N. J.) was administered rapidly to three patients with normal 
RAP. Two of these patients exhibited an elevated control LVEDP and responded to a $500 \mathrm{ml}$ infusion of dextran with a slightly greater increase in LVEDP than in RAP (Figs. 6 and 7). CO was unchanged in one patient but rose in the other from 4.29 to 5.21 liters $/ \mathrm{min}$. In the third patient, the only individual in this series with a normal LVEDP during shock after myocardial infarction, LVEDP rose from 8 to $38 \mathrm{~mm} \mathrm{Hg}$ after infusion of only $300 \mathrm{ml}$ dextran while RAP rose from 6 to $13 \mathrm{~mm} \mathrm{Hg}$. However, most of the rise in LVEDP in this patient could be attributed to atrial contraction, since mean $\mathrm{LV}$ pressure rose only to $12 \mathrm{~mm} \mathrm{Hg}$. CO increased insignificantly after dextran from 4.28 to 4.48 liters/min.

Pulmonary disease. 10 patients exhibited shock as a complication either of severe bilateral bronchopulmo- nary disease (five patients) or acute pulmonary embolism (five patients). RAP averaged $10.5 \mathrm{~mm} \mathrm{Hg}$ in these subjects and LVEDP only $8.1 \mathrm{~mm} \mathrm{Hg}$ (Table I, Fig. 2). A significant correlation between LVEDP and RAP in these patients $(r=0.647, P<0.05)$ formed a regression line deviated sharply toward the RAP axis (Fig. 1). In seven patients RAP was either equal to or higher than LVEDP. The ratio between LVEDP and RAP averaged 0.82 . $\mathrm{CO}$ measured in five subjects averaged 3.75 liters/min (Figs. 3 and 4 ).

Isoproterenol administered to three subjects resulted in an increased CO (Table II). RAP fell or remained constant, but LVEDP rose in two of the patients. Metaraminol infused in one patient produced slight increases in RAP and LVEDP without altering $\mathrm{CO}$ (Table III). Angiotensin increased $\mathrm{CO}$ in another

TABLE II

Hemodynamic Effects of Isoproterenol (I) in Patients with Shock

\begin{tabular}{|c|c|c|c|c|c|c|}
\hline Patient & State & MAP & LVEDP & RAP & HR & $\mathrm{CO}$ \\
\hline & & $m m \mathrm{Hg}$ & $m m \mathrm{Hg}$ & $m m \mathrm{Hg}$ & beats $/ \mathrm{min}$ & liter/min \\
\hline G. R. & $\begin{array}{c}\text { Control } \\
\text { I }\end{array}$ & $\begin{array}{l}98 \\
90\end{array}$ & $\begin{array}{l}28 \\
32\end{array}$ & $\begin{array}{l}9 \\
8\end{array}$ & $\begin{array}{l}72 \\
86\end{array}$ & $\begin{array}{l}1.26 \\
4.08\end{array}$ \\
\hline R. H. & $\begin{array}{l}\text { Control } \\
\text { I }\end{array}$ & $\begin{array}{l}54 \\
56\end{array}$ & $\begin{array}{l}24 \\
22\end{array}$ & $\begin{array}{l}5 \\
5\end{array}$ & $\begin{array}{l}120 \\
144\end{array}$ & $\begin{array}{l}1.83 \\
2.24\end{array}$ \\
\hline E. A. & $\begin{array}{l}\text { Control } \\
\text { I (low dose) } \\
\text { I (high dose) }\end{array}$ & $\begin{array}{l}54 \\
60 \\
64\end{array}$ & $\begin{array}{l}20 \\
20 \\
30\end{array}$ & $\begin{array}{l}8 \\
5 \\
8\end{array}$ & $\begin{array}{l}128 \\
150 \\
162\end{array}$ & $\begin{array}{l}5.21 \\
7.84 \\
9.94\end{array}$ \\
\hline R. B. & $\begin{array}{c}\text { Control } \\
\text { I }\end{array}$ & $\begin{array}{l}60 \\
48\end{array}$ & $\begin{array}{l}22 \\
25\end{array}$ & $\begin{array}{l}11 \\
10\end{array}$ & $\begin{array}{l}75 \\
90\end{array}$ & $\begin{array}{l}3.47 \\
6.58\end{array}$ \\
\hline L. W. & $\begin{array}{c}\text { Control } \\
\text { I }\end{array}$ & $\begin{array}{l}66 \\
74\end{array}$ & $\begin{array}{l}17 \\
16\end{array}$ & $\begin{array}{l}9 \\
4\end{array}$ & $\begin{array}{l}114 \\
126\end{array}$ & $\begin{array}{l}3.06 \\
5.67\end{array}$ \\
\hline E. W. & $\begin{array}{l}\text { Control } \\
\text { I (early) } \\
\text { I (later) }\end{array}$ & $\begin{array}{l}67 \\
75 \\
50\end{array}$ & $\begin{array}{l}18 \\
16 \\
30\end{array}$ & $\begin{array}{l}6 \\
1 \\
6\end{array}$ & $\begin{array}{r}90 \\
124 \\
124\end{array}$ & - \\
\hline L. P. & $\begin{array}{c}\text { Control } \\
\text { I }\end{array}$ & $\begin{array}{l}70 \\
74\end{array}$ & $\begin{array}{l}34 \\
24\end{array}$ & $\begin{array}{l}18 \\
15\end{array}$ & $\begin{array}{l}102 \\
102\end{array}$ & - \\
\hline E. H. & $\begin{array}{c}\text { Control } \\
\text { I }\end{array}$ & $\begin{array}{l}74 \\
76\end{array}$ & $\begin{array}{l}16 \\
22\end{array}$ & $\begin{array}{l}16 \\
16\end{array}$ & $\begin{array}{l}72 \\
96\end{array}$ & $\begin{array}{l}2.91 \\
4.14\end{array}$ \\
\hline L. H. & $\begin{array}{c}\text { Control } \\
\text { I }\end{array}$ & $\begin{array}{l}70 \\
76\end{array}$ & $\begin{array}{l}8 \\
4\end{array}$ & $\begin{array}{l}9 \\
7\end{array}$ & $\begin{array}{r}99 \\
108\end{array}$ & $\begin{array}{l}5.23 \\
8.92\end{array}$ \\
\hline J. D. & $\begin{array}{c}\text { Control } \\
\text { I }\end{array}$ & $\begin{array}{l}56 \\
70\end{array}$ & $\begin{array}{l}16 \\
18\end{array}$ & $\begin{array}{l}16 \\
14\end{array}$ & $\begin{array}{r}88 \\
104\end{array}$ & - \\
\hline L. E. & Control & $\begin{array}{l}80 \\
76\end{array}$ & $\begin{array}{l}17 \\
13\end{array}$ & $\begin{array}{l}6 \\
7\end{array}$ & $\begin{array}{l}114 \\
142\end{array}$ & $\begin{array}{l}4.79 \\
6.70\end{array}$ \\
\hline R. H. & $\begin{array}{c}\text { Control } \\
\text { I }\end{array}$ & $\begin{array}{l}46 \\
50\end{array}$ & $\begin{array}{l}26 \\
24\end{array}$ & $\begin{array}{l}15 \\
13\end{array}$ & $\begin{array}{l}85 \\
90\end{array}$ & $\begin{array}{l}10.26 \\
11.11\end{array}$ \\
\hline E. P. & $\begin{array}{c}\text { Control } \\
\text { I }\end{array}$ & $\begin{array}{l}54 \\
70\end{array}$ & $\begin{array}{l}20 \\
14\end{array}$ & $\begin{array}{r}10 \\
8\end{array}$ & $\begin{array}{l}70 \\
84\end{array}$ & $\begin{array}{l}4.54 \\
8.56\end{array}$ \\
\hline
\end{tabular}


patient by over 1.5 liters $/ \mathrm{min}$, but at the expense of a sharp increase in both RAP and LVEDP. Norepinephrine administered to the same patient resulted in the same increase in $\mathrm{CO}$ but with a slight reduction in cardiac filling pressures. Infusion of $500 \mathrm{ml}$ dextran in five patients increased RAP by an average of $10 \mathrm{~mm}$ $\mathrm{Hg}$ whereas LVEDP increased an average of only 8.2 $\mathrm{mm} \mathrm{Hg}$ (Figs. 6 and 7). After volume expansion RAP was considerably above the normal range in all subjects but LVEDP was still normal in three. The LVEDP: RAP ratio fell in these five patients from 1.16 to 0.87 . $\mathrm{CO}$ increased after dextran from an average of 3.54 to 4.94 liters/min.

Sepsis. The six patients with infections as the apparent precipitating cause of shock exhibited at the time of study either no evidence of ventricular failure or signs of biventricular dysfunction (Table I). Several of the patients had already received therapeutic trials of plasma volume expansion before study. The correlation between RAP and LVEDP ( $r=0.835)$ was highly significant. The values tended to fall between the regression lines for myocardial infarction and pulmonary disease (Fig. 1). RAP averaged $5.8 \mathrm{~mm} \mathrm{Hg}$ and LVEDP $11.1 \mathrm{~mm} \mathrm{Hg}$ (Fig. 2). The ratio of LVEDP to RAP averaged 1.88 . CO in this group usually was higher, averaging 6.29 liters/min (Figs. 3 and 4).

Infusion of vasoconstrictor drugs (norepinephrine, metaraminol, or angiotensin) increased LVEDP sharply in two of three patients whereas RAP was essentially unchanged (Table III). Isoproterenol, on the other hand, reduced LVEDP in three patients (Table II).

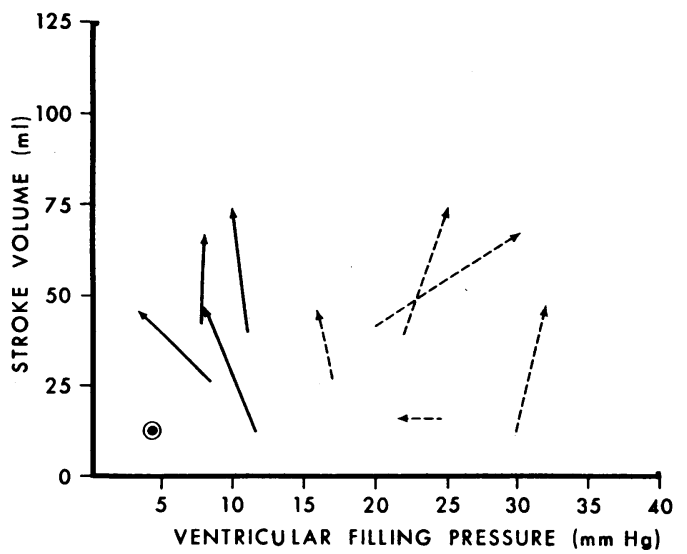

FiguRE 5 Changes in stroke volume and ventricular filling pressures induced by infusion of isoproterenol in five patients with acute myocardial infarction. Solid lines with arrows depict changes in RAP and dashed lines with arrows changes in LVEDP. Dot with circle represents unchanged measurements. Stroke volume increased in four patients while RAP either fell or was unchanged. However, LVEDP increased in three patients and the gradient between LVEDP and RAP was increased in four subjects.

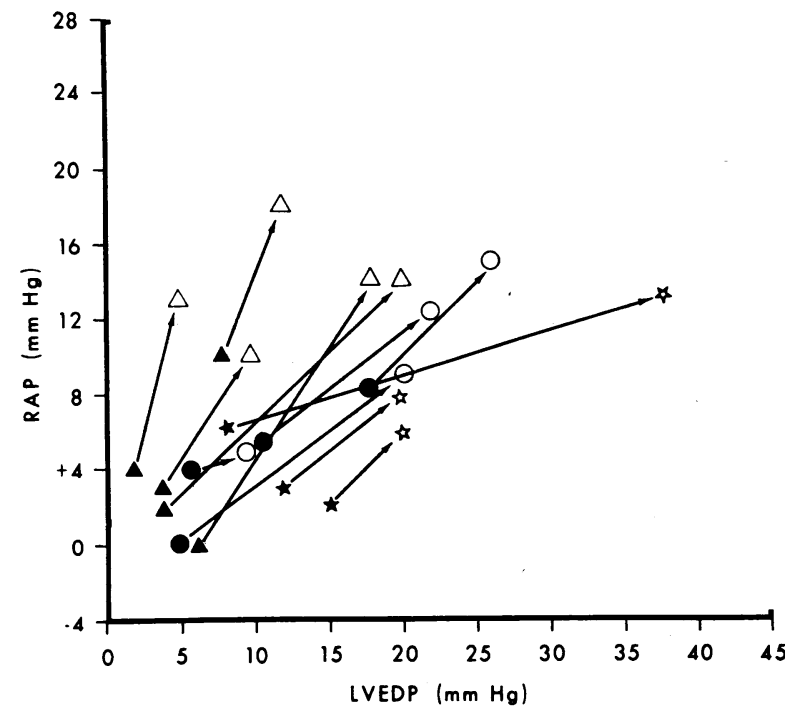

FIgURE 6 Changes in LVEDP and RAP immediately after rapid infusion of dextran in 12 patients. Closed symbols represent values before and open symbols values after volume expansion. (Stars, acute myocardial infarction; triangles, pulmonary disease; circles, sepsis.)

CO was only slightly altered during infusion of vasoconstrictor drugs but rose an average of 2.26 liters $/ \mathrm{min}$ during infusion of isoproterenol.

Dextran infusions in four of these patients induced slightly greater increases in LVEDP (average $9.7 \mathrm{~mm}$ $\mathrm{Hg}$ ) than in RAP (average $6.0 \mathrm{~mm} \mathrm{Hg}$ ) (Figs. 6 and 7). The LVEDP: RAP ratio remained nearly constant. CO rose from an average of 7.40 to 8.51 liters $/ \mathrm{min}$.

\section{DISCUSSION}

Since output from the two ventricles must be equal in any steady-state condition and the functional capacity of the ventricle can be defined by the relationship between its end diastolic volume and stroke volume (22), the relative competence of the ventricles can be assessed by simultaneous measurement of right and left ventricular end diastolic volumes. Because of technical problems involved in attempting to measure ventricular volumes in critically ill patients, relative diastolic fiber lengths in the present study were assessed from pressure measurements. Although the ventricular filling pressure may be an inaccurate guide to ventricular volume when measurements are made at different times or on different subjects, simultaneous comparison of the filling pressures in a subject's right and left ventricle should be relatively independent of variations in heart rate, intrathoracic pressure, and adrenergic activity which might otherwise influence the significance of these measurements (23).

In the present study mean RAP and LVEDP served as indices of the right and left ventricular filling pres- 
sures, respectively. Previous studies have indicated that, in the absence of valvular disease, no significant gradient exists between the right atrium and right ventricle at the end of diastole and that the mean RAP closely approximates the end diastolic pressure in the right ventricle (24). Since the left atrial pressure is normally from 1 to $7 \mathrm{~mm} \mathrm{Hg}$ higher than the $\operatorname{RAP}(23,25,26)$ the left ventricular function curve is situated considerably "to the right" of the right ventricular curve on a conventional Frank-Starling graph relating filling pressure to stroke volume (27). If an isolated impairment of left ventricular function occurred or if left ventricular function were disturbed to a greater extent than that of the right ventricle, LVEDP would surpass RAP by more than the normal gradient. On the other hand, predominant right ventricular dysfunction would shift the right ventricular function curve to the right and elevate RAP relative to LVEDP.

The patients in this series with shock after acute myocardial infarction had predominant left ventricular dysfunction manifested by an elevated LVEDP which surpassed RAP by $8 \mathrm{~mm} \mathrm{Hg}$ or more in 13 of the 14 patients. In the one patient (J. S.) with a normal LVEDP and a normal LVEDP:RAP gradient, acute volume expansion with dextran resulted in a sharp rise in LVEDP which then surpassed RAP by $25 \mathrm{~mm} \mathrm{Hg}$. The observations in this patient suggest that plasma volume depletion may mask the signs of predominant left ventricular failure which usually accompany acute myocardial infarction. The low cardiac outputs in these patients confirmed the presence of severe left ventricular failure. Since myocardial infarcts occur almost exclusively in the left ventricle (15), the impairment of left ventricular performance could be attributed to the loss of functioning muscle, paradoxical systolic expansion of the infarcted area, and (or) functional impairment of neighboring noninfarcted areas of the ventricle (28-30).

In contrast, shock complicating pulmonary embolism or severe lung disease was manifested by a shift to the right of the right ventricular function curve relative to the left ventricular curve. Indeed, in 7 of 10 patients RAP equaled or surpassed LVEDP. These findings are consistent with right ventricular strain associated with elevated pulmonary vascular resistance in pulmonary emboli or extensive parenchymal disease $(16,31)$. Cardiac outputs were usually reduced in these patients, so that right ventricular function apparently was impaired. However, pulmonary arterial pressure probably was considerably increased and function curves utilizing stroke work rather than stroke volume (32) might have suggested less disturbance in right ventricular performance. The normal LVEDP recorded in all five patients with pulmonary embolism lends no support to previous clinical suspicions that left ventricular failure is a common occurrence in acute cor pulmonale (33). However, two patients with emphysema and bronchopneumonia did

TABLE III

Hemodynamic Effects of Norepinephrine (NE), Metaraminol (M), and Angiotensin (A) in Patients with Shock

\begin{tabular}{|c|c|c|c|c|c|c|}
\hline Patient & State & MAP & LVEDP & RAP & HR & co \\
\hline & & $m m \mathrm{Hg}$ & $m m \mathrm{Hg}$ & $m m \mathrm{Hg}$ & beats/min & liters/min \\
\hline E. A. & $\begin{array}{l}\text { Control } \\
\text { NE }\end{array}$ & $\begin{array}{l}50 \\
80\end{array}$ & $\begin{array}{l}12 \\
20\end{array}$ & $\begin{array}{l}3 \\
6\end{array}$ & $\begin{array}{l}150 \\
150\end{array}$ & $\begin{array}{l}4.29 \\
4.76\end{array}$ \\
\hline E. W. & $\begin{array}{c}\text { Control } \\
\mathrm{M}\end{array}$ & $\begin{array}{l}60 \\
72\end{array}$ & $\begin{array}{l}28 \\
26\end{array}$ & $\begin{array}{l}14 \\
12\end{array}$ & $\begin{array}{r}124 \\
96\end{array}$ & - \\
\hline J.S. & $\begin{array}{c}\text { Control } \\
\mathrm{NE}\end{array}$ & $\begin{array}{l}70 \\
86\end{array}$ & $\begin{array}{r}8 \\
17\end{array}$ & $\begin{array}{l}6 \\
8\end{array}$ & $\begin{array}{r}108 \\
96\end{array}$ & $\begin{array}{c}4.28 \\
-\end{array}$ \\
\hline F. W. & $\begin{array}{c}\text { Control } \\
\mathrm{M}\end{array}$ & $\begin{array}{l}48 \\
86\end{array}$ & $\begin{array}{l}2 \\
5\end{array}$ & $\begin{array}{l}4 \\
5\end{array}$ & $\begin{array}{l}80 \\
72\end{array}$ & $\begin{array}{l}4.08 \\
4.09\end{array}$ \\
\hline F. M. & $\begin{array}{c}\text { Control } \\
\mathrm{A} \\
\mathrm{NE}\end{array}$ & $\begin{array}{l}28 \\
70 \\
66\end{array}$ & $\begin{array}{r}8 \\
20 \\
7\end{array}$ & $\begin{array}{r}10 \\
23 \\
8\end{array}$ & $\begin{array}{l}123 \\
138 \\
132\end{array}$ & $\begin{array}{l}3.33 \\
5.00 \\
4.89\end{array}$ \\
\hline L. E. & $\begin{array}{l}\text { Control } \\
\text { NE }\end{array}$ & $\begin{array}{r}76 \\
104\end{array}$ & $\begin{array}{l}12 \\
21\end{array}$ & $\begin{array}{l}5 \\
7\end{array}$ & $\begin{array}{l}112 \\
104\end{array}$ & $\begin{array}{l}4.68 \\
6.19\end{array}$ \\
\hline W. R. & $\begin{array}{c}\text { Control } \\
\text { A }\end{array}$ & $\begin{array}{l}44 \\
66\end{array}$ & $\begin{array}{r}9 \\
14\end{array}$ & $\begin{array}{l}3 \\
3\end{array}$ & $\begin{array}{l}80 \\
92\end{array}$ & $\begin{array}{l}8.80 \\
8.00\end{array}$ \\
\hline E. P. & $\begin{array}{c}\text { Control } \\
M\end{array}$ & $\begin{array}{l}60 \\
70\end{array}$ & $\begin{array}{l}10 \\
10\end{array}$ & $\begin{array}{l}5 \\
5\end{array}$ & $\begin{array}{l}66 \\
84\end{array}$ & - \\
\hline
\end{tabular}


exhibit slight elevations in LVEDP. It is possible that these elderly men had coexistent arteriosclerotic heart disease, but left ventricular failure also could be attributed to hypotension (7), circulating toxins $(9,10)$, lactic acidosis (12), or chronic lung disease (34).

In septic shock the preservation of a fairly normal relationship between LVEDP and RAP implies that no localized defect in cardiovascular function was present. Although cardiac output was normal in some of these patients, low cardiac outputs with elevated filling pressures in others indicated biventricular failure. Whether the cardiac failure in sepsis is due to reduced coronary blood flow or to humoral factors, both ventricles apparently are equally affected. The absence of predominant left ventricular failure in these patients suggests that under these clinical circumstances, in contrast to previous experimental observations (17), right ventricular functional impairment may have hemodynamic effects.

The vasoactive drugs administered to these patients all would be expected to increase cardiac work. During infusion of angiotensin in two patients, a rise in peripheral resistance was accompanied by a constant or increased $\mathrm{CO}$, consistent with our previous observations (35). Since angiotensin lacks a potent inotropic effect (35), the increased left ventricular work was accomplished at least in part by an increase in myocardial fiber length manifested in these patients by a sharp rise in LVEDP. A similar response has been noted in this laboratory within a few minutes after intravenous admin-

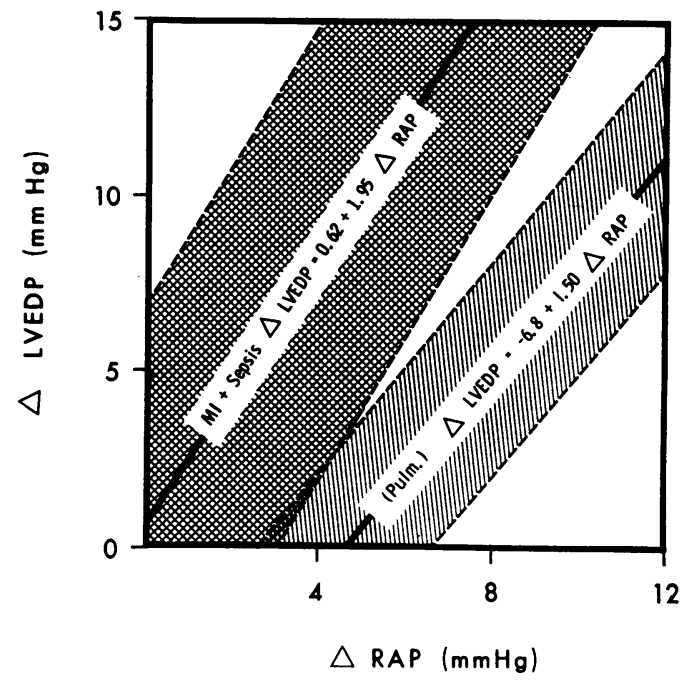

Figure 7 Regression lines for the change in LVEDP related to change in RAP following dextran infusion. The shaded area represents one standard error on either side of the calculated lines. Note that the patients with myocardial infarction and sepsis share a similar regression line which reflects a greater rise in LVEDP than in RAP. In contrast, patients with cor pulmonale exhibit a disprojortionate rise in RAP. istration of digitalis to patients with cardiogenic shock. An acute rise in aortic pressure associated in several patients with a sharp rise in LVEDP has been attributed to a peripheral vasoconstrictor effect of digitalis preceding the inotropic effect (36). The inotropic agents used in this study all would be expected to increase myocardial oxygen consumption (37), whether they induced peripheral vasoconstriction, like norepinephrine and metaraminol (38), or vasodilatation, like isoproterenol (39). Although the inotropic effects of these drugs could allow the ventricle to perform more work without an increase in diastolic volume, the increase in contractility would depend on adequate myocardial oxygen supply (40). CO usually rose only slightly during infusion of metaraminol or norepinephrine, but a sharp rise in ventricular work was associated in three patients with an increase in LVEDP. Infusion of isoproterenol usually led to a considerable increase in CO. It is of interest, however, that LVEDP fell during isoproterenol administration in patients with septic shock, in whom coronary blood flow presumably was adequate to supply the increased myocardial oxygen demands, but often rose in patients with myocardial infarction. In some of these latter patients the peripheral vasodilator effect of isoproterenol led to a reduction in aortic pressure which may have actually reduced coronary flow. Thus, vasoactive drugs apparently may aggravate left ventricular failure in shock by two independent mechanisms: $(a)$ if arteriolar constriction occurs in the absence of a direct inotropic effect, and $(b)$ if an induced increase in cardiac work or myocardial contractility is not accompanied by an adequate rise in coronary blood flow. Furthermore, the changes in LVEDP in these circumstances when left ventricular work was acutely altered often were not accompanied by comparable changes in RAP.

Since rapid volume expansion does not alter the inotropic state of the ventricle, monitoring of the LVEDP and RAP during infusion of dextran affords a description of the relative shape of the ventricular function curves. This information is of particular importance because normal and abnormal cardiac function curves tend to converge at lower ventricular end diastolic pressures and the degree of functional impairment may thus be masked (27). Intravenous infusions, which must traverse the right heart before affecting left ventricular filling, might be expected to result in a disproportionate rise in RAP when administered to a patient with an isolated defect in right ventricular emptying. This response was observed in those patients with primary pulmonary and pulmonary vascular lesions. RAP was increased to abnormally high levels in all patients whereas LVEDP usually rose more slowly and remained within the normal range in three of the five patients studied (Fig. 6). 
In patients with myocardial infarction or sepsis, rapid infusion of dextran led to a slightly greater increase in LVEDP than in RAP. The ratio of the rise in LVEDP compared to the rise in RAP was generally consistent with the normal LVEDP: RAP gradient. In the small group of patients the response in sepsis was not noticeably different than the response in myocardial infarction and the results were therefore pooled (Fig. 7). It is possible that a larger series would reveal a tendency for a predominant rise in LVEDP during volume expansion in myocardial infarction similiar to the response of patient J. S. However, in no instance in any patient with shock have we observed a rise in LVEDP during dextran infusion without a concomitant increase in RAP. When left ventricular performance is severely impaired as in the patients with myocardial infarction, a rise in RAP without much increase in cardiac output signifies functional impairment of the right ventricle. Since RAP was increased initially in most of the patients with shock after myocardial infarction or rose after volume expansion, there usually was hemodynamic evidence of right ventricular failure. It is possible that the myocardial infarction in some of these patients involved the right ventricular wall or septum, or that preexisting left ventricular failure had resulted in chronic right ventricular strain. However, the progressive rise in RAP observed during acute volume loading in patients with predominant left ventricular failure suggests that the right ventricle may serve as a sump which enlarges with the left ventricle as venous return is augmented, thus protecting the lungs from sudden increases in blood volume. Such a functional interdependence of the two ventricles is not surprising considering their anatomic relationship in the same muscular framework (41). Whether this dilatation of the right ventricle should be classified as right ventricular failure or interpreted as a protective reservoir function of the right ventricle is perhaps a matter of semantics. Nonetheless, the observations could cast doubt on the classical hypothesis that right heart failure commonly develops after left heart failure as a result of the chronic strain of an elevated pulmonary arterial pressure (42). Pulmonary artery pressures were not measured in these patients and might well have been elevated, but it is more attractive to postulate that in chronic heart failure an expanded blood volume and (or) a constricted vascular capacitance lead to a gradual increase in venous return which, like acute volume loads, results in dilatation of the right ventricular reservoir.

The evidence of left ventricular failure either initially or after volume expansion in all patients with shock after acute myocardial infarction in this series does not appear to favor reduced cardiac filling as a common fac- tor in the pathogenesis of shock. However, Nixon, Taylor, and Morton (43) reported a patient with low LVEDP and our own previous experience $(14,44)$ and that of others $(45,46)$ has suggested that volume expension may have considerable therapeutic benefit in some patients with myocardial infarction shock. It is possible that this series failed, by chance, to include an individual in whom hypovolemia was the predominant cause of the shock. This syndrome in acute myocardial infarction may be less common today than in the past because of a decline in the use of vasoconstrictor agents, which tend to deplete circulating plasma volume (47). Indeed, Patient J. S., whose control LVEDP was normal, had received a short infusion of norepinephrine just before study. It is also possible that further increments in circulating volume may increase blood flow even in patients with left ventricular failure by allowing the ventricle to operate further out on its impaired function curve. Such was apparently the case in one of our patients with myocardial infarction, in whom cardiac output rose from 4.29 to 5.21 liters/min as LVEDP increased from 12 to $20 \mathrm{~mm} \mathrm{Hg}$ after infusion of $500 \mathrm{ml}$ dextran. More data must be obtained before the relationship between left ventricular volume and left ventricular output after myocardial infarction is understood.

In managing the patient with shock, the physician usually must rely on changes in CVP (RAP) as a guide to the adequacy of cardiac function. The data obtained in this study provide a clearer understanding of the significance of the CVP in various clinical settings. In patients with pulmonary emboli or extensive pulmonary disease, the CVP is often higher than the LVEDP (Fig. 1) and usually rises faster than the LVEDP during volume expansion (Fig. 7). Thus, large increases in CVP may be necessary in these patients to significantly augment left ventricular filling. In septic shock, the CVP probably serves as a fairly reliable guide to LVEDP (Fig. 1) except when vasoactive drugs acutely alter ventricular work. Although a positive correlation was observed between RAP (CVP) and LVEDP in patients with myocardial infarction, the level of the CVP was not a reliable guide to the severity of left ventricular failure (Fig. 1). The disparity between LVEDP and CVP often was further exaggerated during administration of vasoactive drugs (Fig. 5). Fortunately. however, increments in venous return apparently are reflected by a rise in CVP even in the presence of isolated left ventricular failure (Fig. 7). Therefore, pulmonary edema resulting from left heart failure should not be precipitated during dextran infusion without a rise in CVP. However, since the CVP could be nearly normal in patients with severe left ventricular failure, close attention must be given to even small changes in CVP 
during fluid administration when acute myocardial infarction is suspected.

\section{ACKNOWLEDGMENTS}

The authors are indebted to Miss Eleanor Garlisi, R.N., and Mrs. Sally Shaughnessy, R.N., for valuable technical assistance.

This study was supported in part by U. S. Public Health Service Research Grant HE 09785 from the National Heart Institute.

\section{REFERENCES}

1. Kohlstaedt, K. G., and I. H. Page. 1944. Terminal hemorrhagic shock: circulatory dynamics, recognition and treatment. Surgery. 16: 430.

2. Wiggers, C. J. 1947. Myocardial depression in shock. A survey of cariodynamic studies. Amer. Heart J. 33: 633.

3. Crowell, J. W., and A. C. Guyton. 1962. Further evidence favoring a cardiac mechanism in irreversible hemorrhagic shock. Amer. J. Physiol. 203: 248.

4. Alican, F., M. L. Dalton, Jr., and J. D. Hardy. 1962. Experimental endotoxin shock. Circulatory changes with emphasis upon cardiac function. Amer. J. Surg. 103: 702.

5. Starzecki, B., and W. W. Spink. 1968. Hemodynamic effects of isoproterenol in canine endotoxin shock. $J$. Clin. Invest. 47: 2193.

6. Opdyke, D. F., and R. C. Foreman. 1947. A study of coronary flow under conditions of hemorrhagic hypotension and shock. Amer. J. Physiol. 148: 726.

7. Sarnoff, S. J., R. B. Case, P. E. Waithe, and J. P. Isaacs. 1954. Insufficient coronary flow and myocardial failure as a complicating factor in late hemorrhagic shock. Amer. J. Physiol. 176: 439

8. Bing, R. J., and H. Ramos. 1962. The role of the heart in shock. J. Amer. Med. Ass. 181: 871.

9. Gomez, O. A., and W. F. Hamilton. 1964. Functional cardiac deterioration during development of hemorrhagic circulatory deficiency. Circ. Res. 14: 327.

10. Lefer, A. M., R. Cowgill, F. F. Marshall, L. M. Hall, and E. D. Brand. 1967. Characterization of a myocardial depressant factor present in hemorrhagic shock. Amer. J. Physiol. 213: 492.

11. Thrower, W. B., T. D. Darby, and E. E. Aldinger. 1961. Acid-base derangements and myocardial contractility: effects as a complication of shock. Arch. Surg. 82: 56.

12. Wildenthal, K., D. S. Mierzwiak, R. W. Myers, and J. H. Mitchell. 1968. Effects of acute lactic acidosis on left ventricular performance. Amer. J. Physiol. $214: 1352$.

13. Cohn, J. N. 1967. Central venous pressure as a guide to volume expansion. Ann. Intern. Med. 66: 1283 .

14. Cohn, J. N., M. H. Luria, R. C. Daddario, and F. E. Tristani. 1967. Studies in clinical shock and hypotension. V. Hemodynamic effects of dextran. Circulation. 35: 316.

15. Wartman, W. B., and H. K. Hellerstein. 1948. Incidence of heart disease in 2,000 consecutive autopsies. $A n n$. Intern. Med 28: 41 .

16. Sasahara, A. A., J. J. Sidd, G. Tremblay, and O. S. Leland, Jr. 1966. Cardiopulmonary consequences of acute pulmonary embolic disease. Progr. Cardiovasc. Dis. 9: 259.

17. Starr, I., W. A. Jeffers, and R. H. Meade. 1943. The absence of conspicuous increments of venous pressure after severe damage to the right ventricle of the dog, with a discussion of the relation between clinical congestive failure and heart disease. Amer. Heart J. 26: 291.
18. Cohn, J. N. 1967. Blood pressure measurement in shock. Mechanism of inaccuracy in auscultatory and palpatory methods. J. Amcr. Med. Ass. 199: 972.

19. Cohn, J. N., I. M. Khatri, and P. Hamosh. Bedside catheterization of the left ventricle. Amer. J. Cardiol. In press.

20. Hamilton, W. F., Jr., J. W. Moore, J. M. Kinsman, and R. G. Spurling. 1932. Studies on the circulation. Further analysis of the injection method, and of changes in hemodynamics under physiological and pathological conditions. Amer. J. Physiol. 99: 534

21. Braunwald, E., E. C. Brockenbrough, C. J. Frahm, and J. Ross, Jr. 1961. Left atrial and left ventricular pressures in subjects without cardiovascular disease. Circulation. $24: 267$.

22. Patterson, S. W., H. Piper, and E. H. Starling. 1914. Regulation of the heart beat. J. Physiol. 48: 465.

23. Braunwald, E., R. L. Frye, and J. Ross, Jr. 1960. Studies on Starling's law of the heart. Determinants of the relationship between left ventricular end-diastolic pressure and circumference. Circ. Res. 8: 1254.

24. Fowler, N., R. N. Westcott, and R. C. Scott. 1953. Normal pressures in the right heart and pulmonary artery. Amer. Heart J. 46: 264.

25. Opdyke, D. F., J. Duomarco, W. H. Dillon, H. Schreiber, R. C. Little, and R. D. Seely. 1948. Study of simultaneous right and left atrial pressure pulses under normal and experimentally altered conditions. Amer. J. Physiol. 154: 258.

26. Berglund, E. 1954. Ventricular function. VI. Balance of left and right ventricular output: relation between left and right atrial pressures. Amer. J. Physiol. 178: 381.

27. Guyton, A. C. 1963. Circulatory Physiology: Cardiac Output and Its Regulation. W. B. Saunders Company, Philadelphia. 237.

28. Wiggers, C. J. 1945. The functional consequences of coronary occlusion. Ann. Intern. Med. 23: 158.

29. Katz, A. M. 1968. Effects of interrupted coronary flow upon myocardial metabolism and contractility. Progr. Cardiovasc. Dis. 10: 450.

30. Heimbecker, R. O., C. Chen, N. Hamilton, and D. W. G. Murray. 1967. Surgery for massive myocardial infarction: Experimental study of emergency infarctectomy. Surgery. 61: 51 .

31. Harvey, R. M., M. I. Ferrer, D. W. Richards, Jr., and A. Cournand. 1951. Influence of chronic pulmonary disease on the heart and circulation. Amer. J. Med. 10: 719.

32. Case, R. B., E. Berglund, and S. J. Sarnoff. 1954. Ventricular function. II. Quantitative relationship between coronary flow and ventricular function with observations on unilateral failure. Circ. Res. 2: 319.

33. Dexter, L., D. S. Dock, L. B. McGuire, J. W. Hyland, and F. W. Haynes. 1960. Pulmonary embolism. Med. Clin. N. Amer. 44: 1251.

34. Rao, B. S., K. E. Cohn, F. L. Eldridge, and E. W. Hancock. 1968. Left ventricular failure secondary to chronic pulmonary disease. Amer. J. Med. 45: 229.

35. Cohn, J. N., and M. H. Luria. 1965. Studies in clinical shock and hypotension. II. Hemodynamic effects of norepinephrine and angiotensin. J. Clin. Invest. 44: 1494.

36. Cohn, J. N., F. E. Tristani, and I. M. Khatri. 1969. Cardiac and peripheral vascular effects of digitalis in clinical cardiogenic shock. Amer. Heart J. 78: 318.

37. Sonnenblick, E. H., J. Ross, Jr., J. W. Covell, G. A. Kaiser, and E. Braunwald. 1965. Velocity of contraction as a determinant of myocardial oxygen consumption. Amer. J. Physiol. 209: 919. 
38. Sarnoff, S. J., E. Braunwald, G. H. Welch, Jr., and R. B. Case. 1958. Hemodynamic determinants of oxygen consumption of the heart with special reference to the tension-time index. Amer. J. Physiol. 192: 148.

39. Krasnow, N., E. L. Rolett, P. M. Yurchak, W. B. Hood, Jr., and R. Gorlin. 1964. Isoproterenol and cardiovascular performance Amer. J. Med. 37: 514.

40. Daniell, H. B., E. E. Bagwell, and R. P. Walton. 1967. Limitation of myocardial function by reduced coronary blood flow during isoproterenol action. Circ. Res. 21: 85.

41. Brecher, G. A., and P. M. Galletti. 1963. Functional anatomy of cardiac pumping. In Handbook of Physiology. Vol. II. W. F. Hamilton, editor. American Physiological Society, Washington, D. C. 759.

42. Freidberg, C. K. 1956. Diseases of the Heart. W. B. Saunders Company, Philadelphia. 185.
43. Nixon, P. G. F., D. J. E. Taylor, and S. D. Morton. 1968. Left ventricular diastolic pressure in cardiogenic shock treated by dextrose infusion and adrenaline. Lancet. 1: 1230.

44. Cohn, J. N., and M. H. Luria. 1964. Studies in clinical shock and hypotension. The value of bedside hemodynamic observations. J. Amer. Med. Ass. 190: 891.

45. Gunnar, R. M., A. Cruz, J. Boswell, B. S. Co, R. J. Pietras, and J. R. Tobin. 1966. Myocardial infarction with shock. Hemodynamic studies and results of therapy. Circulation. 33: 753.

46. Nixon, P. G. F., H. Ikram, and S. Morton. 1966. Infusion of dextrose solution in cardiogenic shock. Lancet. 1: 1077.

47. Cohn, J. N. 1966. Relationship of plasma volume changes to resistance and capacitance vessel effects of sympathomimetic amines and angiotensin in man. Clin. Sci. 30: 267. 